\title{
Bouncing back: The role of resilience in therapy for school-aged children who stutter
}

\author{
Courtney Leigh Craft, Brent Andrew Gregg \\ Department of Communication Sciences and Disorders, University of Central Arkansas, Conway, AR, USA
}

Purpose: Recent investigations into the area of resilience have applied a risk-and-protective factor model, allowing for the identification of risks, while also identifying positive contextual, social, and individual factors that facilitate individual resilience (Zimmerman, Stoddard, Eisman, Caldwell, Aiyer, and Miller, 2013). Adolescents who stutter are at risk for poor socialemotional development due to adverse speaking experiences and subsequent emotional responses from stuttering. The primary purpose of this pilot investigation was to examine the impact of a specialized group fluency program on promoting resiliency in adolescents who stutter. The secondary purpose of this study was to investigate the relationship between resilience and overall impact of stuttering.

Methods: Five adolescents who stutter ranging from ages 9-17 participated in an 8-week group fluency program, which aimed to increase resiliency by targeting three protective factors known to promote resiliency: self efficacy, social functioning, and peer support. To measure the change in resiliency following intervention, participants completed the The Child and Youth Resilience Measure- 28 (CYRM-28) preceding and following intervention. The correlation between resiliency and the overall impact of stuttering was evaluated through post-test analyses of the Overall Assessment of the Speaker's Experience of Stuttering (OASES) and CYRM-28 scores.

Results: Results indicated a statistically significant increase in resilience and a moderate negative correlation between the CYRM-28 and OASES.

Conclusions: These findings suggest that participation in a specialized, group intervention program can enhance resilience in adolescents who stutter and, consequently, decrease the overall impact of stuttering in their lives.

Keywords: Stuttering, Resilience, Adolescents, Therapy

\section{INTRODUCTION}

For decades, researchers in various fields have taken interest in the mental health of adolescents and the notion of adolescent resilience, postulating why certain individuals are able to "bounce back" quickly from adversity while others go on to develop psychopathology [1]. Many false assumptions and deficit-focused models of resilience have been invalidated [1], and as a result, the resiliency paradigm has shifted to a riskand-protective factor model that focuses on identifying risks and addressing psychopathology in addition to prevention and building strengths [2]. Researchers have begun to simultaneously evaluate and teach methods to enhance individual resilience [2], enabling a context to identify the positive social and individual factors that allow individu-

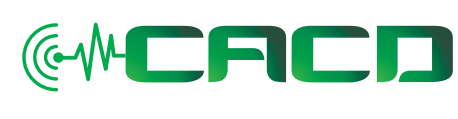

Received: October 9, 2019

Revision: December 11, 2019

Accepted: December 13, 2019

Correspondence:

Brent Andrew Gregg

Department of Communication Sciences and Disorders, University of Central Arkansas, 201 South Donaghey Avenue, Conway, Arkansas 72034, USA

Tel: $+501-852-2823$

Fax: +501-450-5474

E-mail: bgregg@uca.edu

(C) 2019 The Korean Association of SpeechLanguage Pathologists

This is an Open Access article distributed under the terms of the Creative Commons Attribution NonCommercial License (http://creativecommons.org/ licenses/by-nc/4.0/) which permits unrestricted noncommercial use, distribution, and reproduction in any medium, provided the original work is properly cited. 
als to overcome adversity. This has provided researchers with a conceptual framework for understanding adolescent development and informing intervention design [2-4].

There now is a greater understanding regarding the neurobiological basis of resilience in at-risk individuals [5] as an interactive set of mental processes that enable individuals to positively cope with stress and maintain equanimity despite threatening circumstances $[1,6,7]$. In studies of adult brains, those who were resilient exhibited greater activation and functional connectivity between regions of the pre-frontal cortex and amygdala [5]. These pre-frontal regions inhibit amygdala activity, which, in turn, decreases anxiety and enhances emotional regulation. When these regions are interacting properly, development is robust even in the face of severe adversity. Conversely, if these major systems are impaired, prior to or following adverse experiences, then the risk for negative development is much greater.

To date, very little emphasis been placed on investigating the factors that protect people from negative outcomes due to chronic stuttering, leading to a lack of knowledge about resilience processes in people who stutter. Craig, Blumgart, and Tran [8] examined the protective factors functioning in adults who stutter that enhanced resiliency when dealing with the hardships of a chronic fluency disorder. Three significant factors were found to contribute to resiliency: self-efficacy, social functioning, and social support [8]. Self-efficacy refers to a strong sense of control over one's life and environment. It serves as a buffer against distress and proves to be an important factor in maintaining quality of life and happiness [9]. Social functioning is the ability of a person to interact successfully with others. Having fewer barriers to active social interaction also serves as a buffer against psychopathology. Social support is both the perception and actuality that one is cared for, has assistance available from other people, and that one is part of a supportive social network. Social support is valuable because it augments a sense of belonging and well-being. The impact of social support in adults who stutter was recently investigated in a study by Boyle [10] who found that adults who engage in a support group program for their fluency disorder exhibit higher levels of life-satisfaction, self-esteem, and self-efficacy in comparison to those with no support group experience.

Given the findings regarding the contributing factors of resiliency in adults [8], and the influence of group support [10], it is necessary for speech-language pathologists to assess and develop these protective factors in adolescents who stutter. It is well-documented that adolescents who stutter often exhibit a loss of self-confidence and, in comparison to normally fluent peers, exhibit lower levels of self-esteem, increased social anxiety and greater feelings of shame $[11,12]$. These adverse experiences and subsequent emotional responses put these adolescents at risk for poor social emotional development. Therefore, it is necessary to assess and foster individual resilience to the adverse experiences associated with developmental stuttering during this emotionally-vulnerable stage. Despite our knowledge of the negative psychosocial impact of stuttering, the impact of specialized group therapy programs on enhancing resiliency in adolescents who stutter has yet to be investigated.

The purpose of this pilot investigation was to evaluate whether adolescents who stutter show an increase in resiliency measures after participating in an 8-week intensive fluency group therapy program. This empowering, concentrated therapy program will aim to enhance self-efficacy, social functioning, and social support for children who stutter through treatment activities. These protective factors have proven to stimulate resiliency in the adult population [8]. Therefore, it was hypothesized that adolescents who participated in this specialized therapy program also would demonstrate an increase in resiliency measures.

Broadly, resiliency can be defined as the ability of an individual to bounce back from adverse circumstances $[1,6,7]$. The popularity of resilience has inspired over two decades of research and has generated data, methods, and models about resilience, as well as controversies and denunciations [13,14]. Early theories claimed there was something remarkable about resilient children and often described them with words such as "invulnerable" or "invincible" [6]. More recent research, however, has negated those earlier theories $[1,3,6,8]$. Today, there is evidence that resilience most often results from the operation of basic human adaptational systems, with these systems constantly evolving and interacting with one another and the environment.

\section{Neurological implications and the adolescent brain}

In research with adults, neuroscientists have found that resilient individuals exhibit strong connections between regions of the pre-frontal cortex (PFC) and the amygdala [15,16]. The amygdala serves in learning the emotional significance of cues in the environment and is developed long before the PFC [17]. The pre-frontal cortex serves as a cognitive-regulatory function in the brain and integrates processed information 
from various sources and constructs. When these regions are interacting properly, prosocial development is robust even in the face of severe adversity. However, if these major systems are compromised preceding or following adversity, then there is a much greater risk for psychosocial problems [6].

Adolescence is a period involving profound brain maturation, reflected in both white matter changes due to ongoing myelination and fiber organization, as well as grey matter changes, such as synaptic pruning [18-20]. For adolescents, regions of the pre-frontal cortex responsible for processing and regulating emotional responses do not reach full maturity until late adolescence and into early adulthood [21], while the structures of the brain involved in producing emotional responses (e.g., the amygdala, anterior cingulate, and thalamus) are fully developed by early adolescence. This developmental imbalance explains an adolescent's tendency to exhibit maladaptive coping behaviors and be overly sensitive to adversity, such a peer rejection [21]. Therefore, a sensible focus of intervention in adolescents should include emotional processing, which refers to the identification and classifying of emotional expressions in others, as well as evaluating and regulating one's subsequent affective response.

Currently, resiliency researchers are using a risk-and-protective-factor model to evaluate and develop interventions that facilitate individual resiliency [2]. This model not only assesses individuals for risks of poor outcomes but also examines the protective factors that promote resilience [8]. Researchers employing the risk-and-protective-factor model have identified two types of promotive factors: assets and resources. Positive factors within an individual, such as self-efficacy and self-esteem, are considered assets. Resources refers to factors exterior to an individual, such as parental support, mentors, and specialized intervention programs. Together, assets and resources provide adolescents with the attributes necessary for proper development. Researchers examining the promotive factors of resilience in the lives of those confronted by risk have affirmed that the interactions between an individual's resources and assets generate the neural processes that promote resilience to adverse consequences [22,23].

\section{Resiliency, stuttering, and factors involved}

The negative psychosocial aspects of stuttering on children has been well-documented. One of the first investigations in this area was conducted by Craig and his colleagues [8], who examined the protective factors functioning in 200 adults who stutter (age 18 to 85 ) that increased resiliency when dealing with the challenges of a chronic fluency disorder. Results showed that the individuals who were more resilient had superior levels of protective factors (i.e., high self-efficacy, social functioning, and social support), whereas the non-resilient group was found to have a superior number of risk factors (i.e., low self-efficacy, social functioning, and social support). When the investigated factors were entered into a multiple regression analysis, three factors were found to be significant: self-efficacy, social functioning, and social support, underscoring the importance of these factors as contributors to resiliency which, as a result, play an important role in adaptive coping when faced with the adversity associated with stuttering [8].

For adolescents who stutter, adverse consequences often include negative listener reactions, rejection, teasing and bullying [30-34]. Prior research on bullying in adolescents confirmed a higher incidence of bullying in children who stutter in comparison to fluent peers. [33,35-37]. Victims of bullying often experience psychological distress, adjustment problems, poor academic outcomes, negative self-evaluation, depression, and physical symptoms [41,42]. Given the link between victimization and poor psychosocial adjustment, Blood and his colleagues [12] examined the short- and long-term negative psychosocial effects of bullying and stuttering in 54 students who stuttered and 54 students who did not stutter, ranging from 13-17 years-old [12]. Results indicated greater victimization (44.4\%) of students who stutter than students who did not stutter (9.2\%) [12]. Victimization resulting in social isolation and peer rejection can lead to life-long psychosocial problems for adolescents who stutter [43].

Cook and Howell [44] evaluated the relationship between experiences of bullying, self-esteem, and anxiety in children and adolescents who stutter in an effort to determine whether these experiences differed between children aged 9 to 12 and teenagers aged 13 to 17 . Overall, a significant correlation occurred between bullying and "social acceptance" on a selfperception scale. Likewise, an overall significant correlation was found between bullying and state anxiety [44]. The negative correlation found for bullying and the "social acceptance" indicated that a child accepted by his or her peers was less likely to be bullied [44]. The correlation between state-anxiety indicated that if a child experienced levels of bullying, the state anxiety levels when asking for something in public were higher [44]. This is in line with Alm's [45] conclusions that younger children do not typically possess negative traits such as social or general anxiety, but that people with persistent 
stuttering develop social anxiety as a result of their speech problem. Self-efficacy has been found to be a mediating factor of great importance in the resilience process, as it has an active role in determining the severity of psychopathology symptoms [46]. Maciejewski et al. [46] stated that maintaining a healthy self-efficacy, or a strong sense of control over one's life and environment, protected individuals from psychopathology by ameliorating the negative effect of stressful life events experienced. The influence of social support as a protective factor also has been supported in recent stuttering research.

Boyle [10] sought to compare adults who stutter who had participated in self-help support group programs for stuttering with those who had not in terms of self- stigma, self-esteem, self-efficacy, life satisfaction, perceived stuttering severity, and other stuttering-related beliefs. Results indicated that participants with support group experience demonstrated lower internalized stigma, that is, the internalizing of negative societal attitudes. These results support the notion that group support minimizes the internalization of negative attitudes about the self, and that focusing on helping others feel better in a support group context is linked to higher levels of psychological well-being.

More recently, a study by Drucker, Mazzucchelli, and Beilby [49] implemented a parent-administered resilience component in conjunction with stuttering therapy for 28 preschool children who stutter and compared outcomes to a cohort of children who stutter who received stuttering therapy only. A reduction in behavioral and emotional problems and an increase in resilience was observed in the children who stutter whose parents received the additional resilience component of therapy. No significant changes in emotional and behavioral problems in children or parents were observed in the group of children who received fluency therapy only, demonstrating the importance of the implementation of a resilience component into early intervention for stuttering.

Plexico, Erath, Shores, and Burrus [50] evaluated self-acceptance and satisfaction with life with people who stutter and the influence of coping and resilience on the two factors. Forty-seven people who stutter (PWS) and 47 people who do not stutter (PWNS) participated in an online survey assessing areas such as satisfaction with life, coping, avoidance, self-acceptance, and resilience. Results indicated that stuttering was associated with lower self-acceptance at higher levels of avoidant coping and maladaptive coping. People who stuttered who have lower levels of resilience were more likely to have a lower satisfaction with life indicating that higher levels of resilience could serve as a protective factor for having a greater satisfaction with life. Resilience and coping appear to protect against having diminished self-acceptance and satisfaction with life for PWS.

\section{Statement of purpose}

As reviewed above, over the years, the notion of negative affectivity in people who stutter has been widely supported in research $[11,12]$ and is most often examined by researchers and clinicians through the Overall Assessment of the Speaker's Experience of Stuttering (OASES) [51]. However, as has been outlined above, there is a paucity of information on resilience in adolescents who stutter. Given the current findings regarding the neurobiology of resilience, the adolescent brain, and the emotional impact of stuttering, specialized programs that develop and enhance those cognitive processes that foster resilience should be employed in order to protect adolescents from the negative emotional impact of developmental stuttering. This notion is supported by the American SpeechLanguage-Hearing Association (ASHA, 2007), which states that treating communication disorders does not solely involve addressing the structural impairment, but also quality of life through reducing participation restrictions, activity limitations, and barriers created by contextual factors. As a result, several professionals recommend specialized treatment programs that enhance social support, activity, and engagement among PWS $[8,10]$. Therefore, the purpose of this pilot investigation was to measure the effectiveness of a specialized, intensive group therapy program on promoting resiliency in adolescents who stutter. Specific research questions addressed were:

1. Do intensive group therapy programs enhance resilience in adolescents who stutter?

2. Do scores on the CYRM-28 correlate with scores on the OASES?

Resiliency was evaluated from pre-test and post-test scores on the CYRM-28. Additionally, the researcher assessed the correlation between scores on the CYRM-28 and the OASES. It was hypothesized that participants would show an increase in resilience, as measured by the CYRM-28, from the beginning of the intervention program to the end. With regard to the second research question, it was hypothesized that those who exhibited higher scores on the CYRM-28 would exhibit lower scores on the OASES. 


\section{METHODS}

The participants in this pilot investigation included 5 adolescents who stutter and who ranged in age from 10:6 to 17:2, with a mean age of 12:8. Initially, there were 7 adolescents who volunteered their participation in the study. However, one child did not meet all of the inclusion criteria and one child was not included due to attrition. A table of age, gender, and initial stuttering severity (as determined by SSI-4) of the participants is presented below. More detailed participant data are included in Appendix A (Table 1).

Participants were recruited from the University of Central Arkansas (UCA) Fluency Program (a summer therapy program within the UCA Speech-Language-Hearing Center). Because, data indicate that $75 \%$ of children who stutter eventually will recover and will become normally fluent speakers by the age of 4 [52], the age group of participants in this study is representative of children who did not exhibit spontaneous recovery and have persisted with developmental stuttering. Ethnicity was left free to vary, as data reveal that this disorder is fairly stable across race and ethnicity [52]. For the purposes of this research study, participants met the following criteria:

1) Participants were regarded by parents as having a stuttering problem.

2) Participants were regarded by a speech-language pathologist as having a stuttering problem. The diagnosis and severity of stuttering was determined by the Stuttering Severity Instrument 4 (SSI-4).

3) Participants exhibited at least three stuttering-like disfluencies (SLD) per 100 syllables (the minimum level for the identification of stuttering). SLD include part-word repetitions, single-syllable word repetitions, and blocks/ sound prolongations.

4) Participants had no history of neurological disease or seizures. Children with a major organic condition were excluded because their condition could have overshad-

Table 1. Participant ages, gender, and stuttering severity.

\begin{tabular}{lccc}
\hline $\begin{array}{c}\text { Participant } \\
\text { number }\end{array}$ & Age & Gender & $\begin{array}{c}\text { Stuttering } \\
\text { severity }\end{array}$ \\
\hline P1 & $10: 6$ & F & Moderate \\
P2 & $11: 3$ & M & Mild \\
P3 & $11: 8$ & F & Severe \\
P4 & $13: 2$ & M & Mild \\
P5 & $17: 2$ & F & Moderate \\
Average & $12: 8$ & & \\
\hline
\end{tabular}

owed the dynamics of stuttering and resilience that were being studied.

5) English was the primary language spoken by the participants. In children who are bilingual or second-language learners, stuttering may occur because child is mixing vocabulary (code mixing) from both languages in one sentence.

6) Participants exhibited normal hearing and normal or corrected vision. Normal hearing was indicated by a hearing screening from within the past year. Normal or corrected vision was indicated by the parent.

7) Participants exhibited no presence of other speech or language difficulties. Research has shown that a child's language skills can affect his or her fluency.

8) Participants attended a minimum of 10 sessions out of 16 sessions for inclusion in the study.

\section{Pre-intervention assessment}

Three measures were administered to the participants in varying order: the SSI-4, the OASES-S or T, and the CYRM-28. This counterbalancing ensured that no test- learning effect would occur. The SSI-4 was administered to each of the participants in order to determine the levels of stuttering severity. The researcher administered the Overall Assessment of the Speaker's Experience of Stuttering - Teenage (OASES-T) or, depending on age, the Overall Assessment of the Speaker's Experience of Stuttering-School-Age (OASES-S) to each of the participants to evaluate the overall perceptions of their stuttering prior to intervention. Once pre-intervention data had been obtained, the participants engaged in an 8-week stuttering therapy program which integrated components known to increase resiliency processes in individuals.

The SSI-4 evaluates stuttering severity in people 2 years of age or older in the four areas of speech behavior: (1) frequency, (2) duration, (3) physical concomitants, and (4) naturalness of the individual's speech [53]. Frequency is expressed in percent syllables stuttered and converted to scale scores of 2-18. Duration is timed to the nearest one tenth of a second and converted to scale scores of 2-18. The four types of physical concomitants are given a rating by the examiner and converted to scaled scores ranging from 0-20. Two samples of spontaneous speech were obtained, each consisting of at least 200 syllables. The second component of the SSI-4 assesses the client's fluency when reading. As with the spontaneous speech, two samples of at least 200 syllables were obtained from the reading passages and given a score. The client's 
physical behaviors were evaluated from behaviors exhibited by the participant during the speaking and reading samples. The clinician rated physical concomitants with a score of 0 to 5. Each fluency evaluation was audio- and video-recorded for accuracy.

The OASES-S and the OASES-T are simplified versions of the original OASES protocol. These versions are shorter than the original $O A S E S$, with language that is more age-appropriate for younger audiences and targeted to the specific experiences of school-age children and teens. The OASES-S is used to evaluate children ages 7 to 12 . The measure consists of 60 items across 4 sections. The OASES-T, which consists of 80 items across 4 sections, is used to evaluate teenagers ranging from 13 to 17 years of age. In this pilot study, the examiner provided instructions regarding the OASES-T or $S$ and presented the age-appropriate measure to the client for completion.

The CYRM-28 is a 28 -item measure, of which all items are rated on a 5-point scale with higher scores indicating an increased presence of resilience processes [29]. Development of the CYRM-28 was driven by the need for a more inclusive understanding of resilience across cultures and contexts [54,55]. The measure accounts for individual, peer, family, and community resources implicated in resilience processes $[6,56]$. The structure of the CYRM-28 addressed the concerns raised in the Windle et al. [25] review of current resiliency measures and increased its relevance for use in research. After undergoing several phases of testing and evaluation, results established the CYRM-28 as a valid and reliable measure to be utilized by both clinicians and researchers [29]. Since its initial validation, the measure also has been adapted into a 26 -item version for children aged 5 to 9 years old, a 28 -item version used to obtain data from a Person Most Knowledgeable (PMK) about a child/youth's life, and a 28-item version for use with adults (aged 24 and older) [57].

Results from the pilot studies confirm that the CYRM-28 consists of three subscales which reflect the major categories of resilience: (a) individual factors, (b) caregiving, and (c) contextual components [29]. Each subscale contains a collection of questions that indicate the construct's major categories. The first subscale reflects personal skills (5 items), peer support ( 2 items), and social skills ( 4 items). The second subscale examines physical caregiving ( 2 items) as well as psychological caregiving ( 5 items). The third subscale includes contextual components that facilitate a sense of belonging in youth, components related to spirituality (3 items), culture (5 items), and education ( 2 items). Reliability analyses demonstrate that the CYRM-28 and its subscales are internally consistent [29]. Furthermore, no floor or ceiling effects were detected [58]. Since the CYRM-28 is considered a valid measure for longitudinally evaluating the effectiveness of programs pre-intervention and post-intervention [29], the researcher determined it to be a sufficient measure for the purposes of this study. Furthermore, the CYRM-28 provided a short, yet thorough analysis of the three protective factors proven to stimulate resiliency in the adult population.

The structure of the CYRM-28 provides a more thorough understanding regarding the subtle characteristics of resilience processes in young children and examines the active presence of the three subscales in the lives of youth [29]. This 28-item measure provides clinicians with a short, yet detailed analysis of the resilience components that youth are drawing from, as well as those components that are lacking in their lives [29]. The instrument is considered a valid measure to use longitudinally for examining the effectiveness of programs pre-intervention and post-intervention [29].

\section{Intervention}

Following pre-intervention assessment, the children participated in an 8-week specialized program which aimed to enhance resiliency processes, in conjunction with therapy for stuttering. The two, two-hour sessions took place weekly over an 8-week period and were administered by the primary investigator (a graduate clinician in SLP) and her clinical and research mentor (a licensed SLP). Over the course of the two hours, each child participated in traditional stuttering treatment (both individual and group) for 50 minutes and in the resilience program for 50 minutes. All children participated in both stuttering group treatment and resilience program together. In recent years, many authors have embraced the idea that stuttering is a multidimensional disorder $[59,60]$ and that people who stutter are a heterogeneous group. Moreover, the severity of stuttering a person exhibits may be only moderately related-or even unrelated - to the adverse psychosocial impact he or she experiences [61-63]. Therefore, for this study, treatment plans included multiple goals tailored to the unique needs of the individual. The stuttering program here employed a comprehensive approach to treatment which addressed increased fluency and psychosocial goals. In short, the goals and activities aimed to minimize the adverse impact of stuttering on a child's life by enhancing the three aforementioned factors known to promote resilience: self-efficacy, social functioning, and social support [62]. Examples of these 
goals included increasing self-confidence, improving communication skills, managing bullying effectively, acceptance of stuttering, reducing secondary behaviors, and minimizing avoidance [62]. These goals were targeted through a resiliency curriculum developed by the researcher which targeted selfefficacy, social functioning, and social support over a series of 10 lessons. A brief description of each of the lessons is included in Appendix B.

In line with Zebrowski's most recent research regarding adolescent motivation [64], the stuttering program incorporated the aforementioned elements proven to enhance adolescents' motivation to participate in the therapy process. A therapeutic alliance was facilitated through motivational interviewing. Motivational interviewing was incorporated to build rapport and trust between the client and clinician and allowed the client to share about the impact of stuttering on his/her life, providing the clinician with a more thorough understanding of how to facilitate progress. The stuttering program facilitated communicative competence, by focusing on the 5 aspects of communicative competence: attentiveness, assertiveness, confidence, pro-activeness, and desensitization. Peer support was embedded in the program through team building activities, small group discussions, large group discussions, and daily outside experiences.

\section{Post-intervention assessment data analysis}

Following intervention, the participants were administered the OASES-S or T and the CYRM-28 to obtain post-treatment outcome data. Development of resilience factors in subjects was assessed using a paired samples $t$-test. More specifically, a paired samples $t$-test was conducted to compare the means on the CYRM-28 pre- and post- therapy. A non-parametric Spearman correlation analysis was used to assess the relationship between ordinal scores on the CYRM-28 and scores on the OASES-S or $T$.

\section{RESULTS}

The main purpose of this study was to measure the effectiveness of a specialized, intensive group therapy program on promoting resiliency in adolescents who stutter and to assess the correlation between post-intervention scores on the CYRM-28 and the OASES. As previously mentioned, the investigator administered both the CYRM-28 and the OASES to each of the participants preceding and following intervention. With regard to the first research question, the investigator hy- pothesized that, as a group, there would be an increase in scores on the CYRM-28 following the 8-week intervention program. With regard to the second research question, the investigator hypothesized that, as a group, the average OASES score would be negatively correlated with the average CYRM28 score following intervention.

\section{CYRM-28 Measures Pre- and Post- Intervention Group data}

Prior to intervention, the group demonstrated an average score of 106.8 out of a possible 140 on the CYRM-28. Following intervention, the group exhibited an increase in the CRYM-28, demonstrating an average score of 120 . In line with the proposed data analysis for this portion of the study, a paired samples $t$-test was conducted to determine if the preand post- treatment measures were statistically significant. Results of the $t$-test showed that, among participants who participated in the 8-week program $(N=5)$, there was a statistically significant difference between scores on the CYRM-28, preceding intervention ( $M=106.80, S D=9.93)$ and following intervention $(M=120.00, S D=10.61), t(4)=9.0233, p \leq 0.05$, $C I_{95}$-17.26, -9.14. Therefore, findings supported the investigator's hypothesis. A summary of CYRM-28 group data is provided in Table 2.

A summary of the statistics for the $t$-test follows in Table 3.

\section{Individual Trends of CYRM-28 scores pre- and post- intervention}

The CYRM-28 has three sub-scales: individual capacities/resources, relationships with primary caregivers and contextual factors that facilitate a sense of belonging. Since the focus of

Table 2. Group average score on the CYRM-28 preceding and following intervention

\begin{tabular}{lcc}
\hline & $\begin{array}{c}\text { CYRM-28 } \\
\text { Pre-intervention }\end{array}$ & $\begin{array}{c}\text { CYRM-28 } \\
\text { Post-intervention }\end{array}$ \\
\hline Group average & 106.8 & 120 \\
\hline
\end{tabular}

Table 3. Group statistics for paired samples t-test preceding and following intervention

\begin{tabular}{lcc}
\hline Group & $\begin{array}{c}\text { CYRM-28 } \\
\text { Pre-intervention }\end{array}$ & $\begin{array}{c}\text { CYRM-28 } \\
\text { Post-intervention }\end{array}$ \\
\hline Mean & 106.80 & 120.00 \\
SD & 9.83 & 10.61 \\
SEM & 4.40 & 4.74 \\
N & 5 & 5 \\
\hline
\end{tabular}


this investigation was to examine individual resiliency, the investigator evaluated the individual capacities sub-scale. The individual capacities sub-scale can be divided further into three specific areas: personal skills, peer support, and social skills. Given that the intervention aimed to increase self-efficacy, peer support, and social functioning, the investigator was primarily interested in evaluating personal skills, peer support, and social skills following intervention. The items measuring personal skills reflected perceived self-efficacy and the items measuring peer support and social skills reflected the other two aforementioned factors known to enhance resilience. A summary of individual scores and the group average for each of the three specific areas evaluated within the personal capacities subscale prior to intervention are in featured in the tables below (Tables 4-6).

Overall, participant one exhibited an increase on the CYRM28 following intervention. With regard to the three areas comprising the individual capacities sub-scale, there was no difference exhibited in personal skills. The participant did, however, demonstrate an increase in peer support and social skills.

In comparison to the other participants, participant two exhibited the lowest scores on the CYRM-28 both preceding and following intervention. Overall, the child did still exhibit and increase on the CYRM-28 following intervention. With

Table 4. Participant numbers and ages, individual pre-intervention CYRM28 scores, and individual post-intervention CYRM-28 scores

\begin{tabular}{lcc}
\hline $\begin{array}{c}\text { Participant } \\
\text { number \& age }\end{array}$ & $\begin{array}{c}\text { CYRM-28 } \\
\text { Pre-intervention }\end{array}$ & $\begin{array}{c}\text { CYRM-28 } \\
\text { Post-intervention }\end{array}$ \\
\hline P1- 10:6 & 106 & 115 \\
P2- 11:3 & 92 & 106 \\
P3- 11:8 & 119 & 132 \\
P4- 13:2 & 106 & 118 \\
P5- 17:2 & 111 & 129 \\
\hline
\end{tabular}

Table 5. Participant numbers and ages, personal skills scores pre-intervention, peer support scores pre-intervention, social skills scores pre-intervention, and group average

\begin{tabular}{lccc}
\hline $\begin{array}{c}\text { Participant } \\
\text { number \& age }\end{array}$ & Personal skills & Peer support & Social skills \\
\hline P1- 10:6 & 21 & 7 & 14 \\
P2- 11:3 & 19 & 7 & 11 \\
P3- 11:8 & 20 & 9 & 18 \\
P4- 13:2 & 19 & 9 & 13 \\
P5- 17:2 & 15 & 8 & 15 \\
Group average & 18.8 & 9.6 & 14.2 \\
\hline
\end{tabular}

regard to the three areas comprising the individual capacities sub-scale, only an increase in social skills was demonstrated. Participant two exhibited a decrease in peer support, which decreased the group average. Scores on the personal skills sub-set remained constant preceding and following intervention. It should be noted that participant two only attended 10 of the 16 sessions, in comparison to the other participants who attended a minimum of 14 of the 16 sessions.

Participant three exhibited the highest scores on the CYRM28 preceding and following intervention. Overall, the participant demonstrated an increase on the CYRM-28 following intervention. With regard to the three areas comprising the individual capacities sub-scale, an increase was demonstrated in both personal skills and social skills. No change was demonstrated in peer support, as participant three exhibited a high score of 9 out of a possible 10 preceding and following intervention.

Overall, participant four demonstrated an increase on the CYRM-28 following intervention. With regard to the three areas comprising the individual capacities sub-scale, a slight decrease was exhibited in the personal skills sub-set. An increase was observed, however, in the areas of peer support and social skills. Participant five demonstrated the greatest increase in resilience scores amongst all the participants. With regard to the three areas comprising the individual capacities sub-scale, the greatest increase was exhibited in the personal skills sub-set. An increase also was demonstrated in peer support and social skills.

\section{OASES Measures Pre- and Post-intervention Group data}

Prior to intervention, the group demonstrated an average score on the OASES of 2.19, indicating that, overall, developmental stuttering had a mild/moderate impact. Following in-

Table 6. Participant numbers and ages, personal skills scores post-intervention, peer support scores pre-intervention, social skills scores post-intervention, and group average

\begin{tabular}{lccc}
\hline $\begin{array}{c}\text { Participant } \\
\text { number \& age }\end{array}$ & Personal skills & Peer support & Social skills \\
\hline P1- 10:6 & 21 & 10 & 18 \\
P2- 11:3 & 19 & 5 & 14 \\
P3- 11:8 & 21 & 9 & 20 \\
P4- 13:2 & 18 & 10 & 16 \\
P5- 17:2 & 24 & 10 & 18 \\
Group average & 20.6 & 8.8 & 17.2 \\
\hline
\end{tabular}


Table 7. Group average score on the OASES preceding and following intervention

\begin{tabular}{lcc}
\hline & $\begin{array}{c}\text { OASES } \\
\text { Pre-intervention }\end{array}$ & $\begin{array}{c}\text { OASES } \\
\text { Post-intervention }\end{array}$ \\
\hline Group Average & 2.19 & 2.08 \\
\hline
\end{tabular}

Table 8. Participant numbers and ages, individual pre-intervention OASES scores, and individual post-intervention OASES scores

\begin{tabular}{lcc}
\hline $\begin{array}{c}\text { Participant } \\
\text { number \& age }\end{array}$ & $\begin{array}{c}\text { OASES } \\
\text { Pre-intervention }\end{array}$ & $\begin{array}{c}\text { OASES } \\
\text { Post-intervention }\end{array}$ \\
\hline P1- 10:6 & 2.40 & 2.25 \\
P2- 11:3 & 2.30 & 2.31 \\
P3- 11:8 & 2.27 & 2.07 \\
P4- 13:2 & 2.20 & 2.00 \\
P5- 17:2 & 1.76 & 1.76 \\
\hline
\end{tabular}

tervention, the group demonstrated an average score of 2.08, indicating that the overall impact of stuttering remained mild/ moderate following intervention. A summary of the average OASES score pre- and post-intervention are provided in the table below (Table 7).

\section{Individual Trends of OASES scores pre- and post- intervention}

Overall, none of the participants exhibited a statistically significant decrease in overall impact of stuttering following intervention. As mentioned above, this is likely due to the fact that scores were already quite low. A summary of individual OASES scores preceding and following intervention is provided in Table 8.

A non-parametric Spearman correlation analysis was conducted to determine the relationship between post-intervention $C Y R M-28$ scores and post-intervention OASES scores. Results of the analysis, $(R=-0.7$ and $p=0.188)$, revealed a moderate negative correlation between the two measures, indicating that as resiliency increases, the overall impact of stuttering decreases. These results are in line with the investigator's original hypothesis that there would be negative correlation between the two measures. A summary of the statistics of the Spearman correlation analysis is provided in Table 9.

\section{DISCUSSION}

The primary purpose of this study was to evaluate whether adolescents who stutter demonstrated an increase in resiliency measures after participating in an 8-week intensive
Table 9. Statistics for non-parametric Spearman correlation analysis of CYRM-28 post-intervention scores and OASES post-intervention scores

\begin{tabular}{lcc}
\hline Spearman's rho & $\begin{array}{c}\text { CYRM-28 } \\
\text { Post-intervention }\end{array}$ & $\begin{array}{c}\text { OASES } \\
\text { Post-intervention }\end{array}$ \\
\hline Correlation coefficient & 1.000 & -0.700 \\
Sig (2-tailed) & & 0.188 \\
N & 5 & 5 \\
\hline
\end{tabular}

group therapy program. Given the negative psychosocial impact of stuttering and emotional vulnerability of adolescents, a secondary purpose of this study was to evaluate the relationship between resiliency and the overall impact stuttering has in the lives of adolescents. With regard to the first research question evaluating resiliency, a statistically significant increase in resiliency was demonstrated at the conclusion of the program, as measured by the CYRM-28. With regard to the second research question, a moderate negative relationship was demonstrated between the two measures, indicating that as resiliency increased, the overall impact of stuttering decreased. Both findings support the initial hypotheses. A discussion of the results of each research question is presented below, followed by the clinical and theoretical implications of these findings.

In contrast to the Craig et al. [8] study, which focused on examining the protective factors that stimulate resilience in adults who stutter, the current study examined these protective factors in the adolescent population. Furthermore, the current study evaluated change in resiliency following participation in a specialized intervention program. Previously, researchers have examined the protective factors present or absent in at-risk adults and adolescents, but very few researchers have evaluated the development of these protective factors within at-risk individuals. However, given what we know about resilience and the changes that occur in the adolescent brain, an examination of the development of these resiliency processes through specialized intervention was warranted. Again, since the CYRM-28 is considered a valid measure for longitudinally evaluating the effectiveness of programs preintervention and post-intervention [29], the researcher determined it to be a sufficient measure for the purposes of this study. Furthermore, the CYRM-28 provided a short, yet thorough analysis of the three protective factors proven to stimulate resiliency in the adult population.

Increase in adolescent resilience following intervention Following participation in the program, the group demon- 
strated an increase in two of the three respective subscales of the CYRM-28 that measured the aforementioned protective factors. It should be noted, however, that all participants demonstrated high levels of resiliency at the outset of the intervention program. Despite this fact, the statistically significant increase exhibited at the conclusion of the program suggests that participation in a specialized intervention program aimed at increasing adolescent resilience within the framework of developmental stuttering is effective regardless the adolescent's initial level of resiliency. Regarding the individual subscales of the CYRM-28, an increase was demonstrated only in the Personal Skills subscale and the Social Skills subscale, which evaluated perceived self-efficacy and social functioning respectively. Of the three aforementioned protective factors targeted in the program, perceived self-efficacy and social functioning were targeted more directly during intervention than peer support. Thus, it is not surprising that the participants demonstrated the greatest improvement in these areas. Each participant was given multiple opportunities to enhance self-efficacy and social functioning by increasing their proficiency using fluency-facilitating techniques, increasing their knowledge of developmental stuttering, discussing personal fears and difficulties associated with stuttering, evaluating personal strengths, and identifying the automatic thoughts that often precede or follow moments of stuttering.

When evaluating individual trends regarding perceived selfefficacy, participant five demonstrated the greatest increase in resilience following intervention. Given that participant five was the oldest participant (17:2), this finding supports Avci et al.s [65] study, which suggests that resilience involves the effective use of cognitive skills to cope with adversity. The maturation of cognitive skills, or executive function (EF) skills, enables adolescents to direct their thoughts and actions according to internal goals [66]. Enhanced executive functioning is demonstrated by an increase in mental flexibility, accurate appraisal of personal skills, the ability to self-monitor appropriately, and problem-solve more effectively [67]. Thus, executive functioning skills play a pivotal role in the way the sense of self is constructed during adolescence.

Prior research indicates that adolescent self-perceptions are unfixed and that ratings of self-concept change during adolescence as a result of cognitive development [8]. Younger adolescents often demonstrate higher and more unrealistic levels of perceived self-efficacy due to their cognitive inability to construct complex representations of themselves. Research- ers assert, however, that this unduly high self-concept declines as children mature, when cognitive development leads to a more realistic understanding of the self and when external feedback from peers reveal personal weaknesses [68]. This continued decline in self-concept during adolescence has appeared to be robust across population subgroups [69].

Results of the present study supported this notion and were reflected in pre-intervention scores of perceived self-efficacy on the CYRM-28. Prior to intervention, the youngest participant (10:6) scored the highest of all the participants on the subscale evaluating self-efficacy, while participant five, the oldest participant (17:2), exhibited the lowest score. Following intervention, however, participant five exhibited a significant increase in perceived self-efficacy, while participant one did not demonstrate any change at the conclusion of the program. Visual inspection of post-intervention social functioning scores revealed no individual trends in age or gender, as all participants demonstrated an increase in social functioning following intervention. As previously mentioned, social functioning was targeted by allowing participants to develop proficiency using fluency-facilitating techniques through a variety of speaking situations of increasing difficulty. Therefore, it is not surprising that all participants demonstrated an increase in this skill. With regard to the Peer Support subscale, 3 of the 5 participants demonstrated improvement at the conclusion of intervention, one participant demonstrated a decrease post-intervention and one participant demonstrated no change following intervention. These outcomes should be interpreted with caution, as no changes were of statistical significance. While insignificant, the decrease in perceived peer support exhibited by participant two caused an overall decrease in the group average post-intervention.

There are two attributing factors, however, that warrant consideration. First, participant attendance must be considered, as those with the highest rate of attendance demonstrated an increase. Participant two, who exhibited a slight decrease, attended the minimum number of sessions required for inclusion in the study. Furthermore, participant two was not present during the sessions that peer support was directly targeted in discussion. Participant three, who exhibited no change, also exhibited a lower rate of attendance in comparison to the three participants whose perceived peer support score increased. A second contributing factor to be considered is the level of perceived peer support at the outset of intervention. Both participant two and three exhibited higher levels of peer support (90\%) prior to intervention, than the 
three participants that demonstrated an increase.

\section{Evaluating the relationship between the CYRM-28 and the OASES}

Given the small sample size, it is difficult to draw any strong conclusions regarding the relationship between the two measures. Analysis of the data suggests that as resilience increases, the overall impact of stuttering decreases. Given the statistically significant increase demonstrated on the CYRM-28, one could assume that there also would be a statistically significant decrease exhibited on the OASES following intervention. However, results of the current study did not support this assumption. In fact, some participants exhibited an increase in stuttering impact, according to OASES subtest scores following intervention. Taking into account the nature of the intervention, it is probable that participation in the program heightened awareness of stuttering, and consequently, an increase in overall impact following intervention.

\section{Theoretical and clinical implications}

Theoretically, a resiliency paradigm provides researchers and clinicians with insight into the protective factors functioning or absent in adolescents' lives that can help guide intervention, broadening our understanding of the processes by which adolescents overcome adversity. From a clinical standpoint, a resiliency framework provides clinicians with a cohesive structure that can be used for counseling adolescents who are vulnerable to poor psychosocial development due to the stress of a communication impairment. The curriculum developed for this study utilized techniques derived from Cognitive Behavioral Therapy (CBT) and encompassed all three elements, or protective factors, known to facilitate resilience and regulate emotion-processing brain networks [70,71]. Given what we know about the developmental trajectory of the brain, it is understood that cognitive appraisal is difficult, if not impossible, for adolescents to achieve independently. Therefore, it is necessary for speech-language pathologists to not only address stuttering behaviors in treatment, but also to aid adolescents in the cognitive evaluation of the individual adversities associated with developmental stuttering.

While this is not the first study to investigate the impact of specialized intervention in adolescents who stutter, this is the first study to investigate the impact of intervention on enhancing resilience in adolescents. A study conducted by Fry, Millard, and Botterill [72] sought to investigate the impact of an intensive treatment program in reducing overt and covert as- pects of stuttering in 3 male participants ranging from ages 17-18. Results from the study provided evidence that specialized therapy programs were effective in reducing covert and overt stuttering behaviors. While results of the Fry et al. [72] study substantiated the effectiveness of a holistic intervention program employing CBT technique in stuttering treatment, the findings only provided insight regarding the impact of intervention for older, male adolescents. In terms of developing a comprehensive treatment program, this data is limiting, as we now have evidence of the profound cognitive changes that occur during adolescence.

Taken together, findings from the present study combined with the Fry et al. [72] findings suggest that a holistic, cognitive intervention program is beneficial for enhancing self-efficacy across the span of adolescence. In both studies, an increase on measures evaluating self-efficacy was demonstrated following intervention. As mentioned previously, the curriculum developed for the present investigation incorporates techniques of CBT, which engages and strengthens the developing pre-frontal cortex. Increased activation in the pre-frontal cortex regions leads to better regulation of negative emotional states which, in turn, leads to a stronger sense of self-efficacy [73]. From a fluency standpoint, providing adolescents with repeated opportunities to practice using stuttering-modification and fluency- facilitating techniques in speaking situations of increasing difficulty serves as a positive, contextual protective factor that enhances both self-efficacy and social functioning skills. Lastly, being able to improve social functioning skills and cognitively evaluate the impact of developmental stuttering in the presence of supportive, age-matched peers can serve as a protective factor that enhances self-esteem, self-efficacy, and overall life satisfaction [10].

It is important to consider the unique, positive impact of group intervention for adolescents, as extensive developmental research has demonstrated that adolescence is a time characterized by increased importance of peer relationships and sensitivity to rejection [74]. Further substantiating this notion, Zebrowski's research [64], which investigated the factors influencing adolescent motivation to manage stuttering [64], revealed peer support as one of the important factors that facilitates responsiveness to treatment. Prior qualitative research suggests that adolescents enjoy the camaraderie of group therapy. Group intervention programs provide adolescents with positive and substantially different experiences from those they might encounter in an individual therapy setting [57]. Current research on neuroplasticity suggests that 
positive emotional states can trigger lasting, durable changes in the structure and function of the brain which promote further adaptive thoughts and behaviors [73]. Therefore, taking the aforementioned information into consideration, a group intervention program for adolescents who stutter that incorporates cognitive training is justified.

\section{Limitations}

The greatest limitation to the present study was the small sample size. Having only 5 participants made it difficult for the researcher to identify trends and assert any definite conclusions regarding treatment outcomes. Moreover, despite the high internal validity of single-subject studies, results of single-subject studies cannot be generalized. This limitation can be addressed, and validity strengthened, by replication. A second limitation to the current study involves test administration procedures, as the CYRM- 28 was the only measure administered audibly. Administering the measure audibly allowed the researcher to ensure each participant's comprehension of test items. Unlike the CYRM-28, the OASES was completed independently by the participants. Taking into consideration the individual variability and discrepancies demonstrated on OASES subtests, it is unclear whether the discrepancies can be attributed to inaccurate comprehension of measure items or other extraneous factors. However, given that the main focus of this study was to evaluate the increase in resilience, this limitation did not significantly impact interpretation of the outcome.

\section{Future directions}

Research that applies resiliency theory provides a common framework that can be replicated across different populations and contexts. Therefore, it would be beneficial to investigate resilience in other at-risk populations, such as adolescents with reading difficulties and/or diagnosed with dyslexia, hearing loss, as well as in adolescents who are recovering from traumatic brain injury. Like developmental stuttering, each of these disorders put adolescents at a higher risk for having low self-esteem, becoming the target of bullying, experiencing feelings of isolation, and developing psychopathology [7577]. Given what we know about neuroplasticity and the adolescent brain, an investigation of the structures involved in resilient responses is also warranted. Recent research at Vanderbilt University (2014) investigated the neurocircuitry underlying risk and resilience to social anxiety disorder in adolescence. Using fMRI, the researchers were able to measure brain activation of the prefrontal cortex, amygdala, and insula [5]. Therefore, it would be beneficial to use fMRI to more thoroughly examine the activation and function of the regions of the brain responsible for resilient responses preceding and following participation in a specialized group intervention program. Finally, given the rapid and profound cognitive development that occurs during adolescence, more extensive follow up is necessary in order to determine the long-term impact of intervention.

These preliminary findings not only shed light on the protective factors involved in resilient responses to adversity in adolescents who stutter, but further substantiate the effectiveness of a strengths-based approach to intervention. The present study provides clinicians with a structured, comprehensive framework for counseling clients and designing specialized intervention programs that enhances resiliency processes in adolescents with chronic communication impairments, such as persistent developmental stuttering. As more clinicians employ a strengths-based, resilience framework in intervention and more data become available, it will become possible to examine the trends and/or variability in responses to treatment. We can also begin to identify which protective factors have the most positive impact on intervention outcomes. With further evaluation, we will be able to more thoroughly investigate the neurobiological changes that result from participation in a specialized, cognitive intervention program and the psychosocial impact it has on adolescents with chronic communication disorders.

\section{REFERENCES}

1. Southwick SM, Bonanno GA, Masten AS, Panter-Brick C, Yehuda R. Resilience definitions, theory, and challenges: Interdisciplinary perspectives. European Journal of Psychotraumatology. 2014;5:1.

2. Zimmerman MA, Stoddard SA, Eisman AB, Caldwell CH, Aiyer SM, Miller A. Adolescent resilience: Promotive factors that inform prevention. Child Development Perspectives. 2013;7:215-220.

3. Fergus S, Zimmerman MA. Adolescent resilience: A framework for understanding healthy development in the face of risk. Annual Review of Public Health. 2005;26:399-419.

4. Zimmerman MA, Brenner AB. Resilience in adolescence: Overcoming neighborhood disadvantage. In Reich J., Zautra A. J., Hall J. S. (Eds.), Handbook of adult resilience. New York, NY: Guilford Press, 2010;283-308.

5. Clauss JA, Avery SN, VanDerKlok RM, Rogers BP, Cowan RL, Benningfield MM, et al. Neurocircuitry underlying risk and resilience to social anxiety disorder. Depression \& Anxiety (1091-4269). 2014; 31:822-833. 
6. Masten AS. Ordinary magic. American Psychologist. 2001;56:227.

7. Zolkoski SM, Bullock LM. Resilience in children and youth: A review. Children \& Youth Services Review. 2012;34:2295-2303.

8. Craig A, Blumgart E, Trana Y. Resilience and stuttering: Factors that protect people from the adversity of chronic stuttering. Journal of Speech, Language \& Hearing Research. 2011;54:1485-1496.

9. Cummins RA. Fluency disorders and life quality: Subjective wellbeing vs. health-related quality of life. Journal of Fluency Disorders. 2010;35:161-172.

10. Boyle MP. Assessment of stigma associated with stuttering: development and evaluation of the self-stigma of stuttering scale (4S). Journal of Speech, Language \& Hearing Research. 2013;56:15171529.

11. Hugh-Jones S, Smith PK. Self-reports of short- and long-term effects of bullying on children who stammer. British Journal of Educational Psychology. 1999;69:141-158.

12. Blood GW, Blood IM, Tramontana GM, Sylvia AJ, Boyle MP, Motzko GR. Self-reported experience of bullying of students who stutter: Relations with life satisfaction, life orientation, and self-esteem. Perceptual \& Motor Skills. 2011;113:353-364.

13. Luthar SS, Cicchetti D. The construct of resilience: A critical evaluation and guidelines for future work. Child Development. 2000; 71:543.

14. Masten AS, Coatsworth JD. The development of competence in favorable and unfavorable environments. American Psychologist. 1998;53:205.

15. Davidson RJ, McEwen BS. Social influences on neuroplasticity: Stress and interventions to promote well-being. Nature Neuroscience. 2012;15:689-695.

16. Siddiqui SV, Chatterjee U, Kumar D, Siddiqui A, Goyal N. Neuropsychology of prefrontal cortex. Indian Journal of Psychiatry. 2008;50:202-208.

17. Casey BJ, Jones RM, Hare TA. The Adolescent Brain. Annals of the New York Academy of Sciences. 2008;1124:111-126.

18. Harris JJ, Reynell, C, Attwell, D. The physiology of developmental changes in BOLD functional imaging signals. Developmental Cognitive Neuroscience. 2011;1:199-216.

19. Lebel C, Beaulieu C. Longitudinal development of human brain wiring continues from childhood into adulthood. Journal of Neuroscience. 2011;31:10937-10947.

20. Petanjek Z, Judaš $M$, Šimić G, Rašin MR, Uylings HBM, Rakic $P$, et al. Extraordinary neoteny of synaptic spines in the human prefrontal cortex. Proceedings of the National Academy of Sciences of the United States of America. 2011;108:13281-13286.

21. Nelson EE, Leibenluft E, Mcclure EB, Pine DS. The social re-orientation of adolescence: A neuroscience perspective on the process and its relation to psychopathology. Psychological Medicine. 2005;35:163-174.

22. Luthar SS. Resilience in development: A synthesis of research cross five decades. In D. Cicchetti \& D. Cohen (Eds.), Developmental psychopathology: Risk, disorder, and adaptation. Hoboken, NJ: Wiley. 2006;3:739-795.

23. Bottrell D. Understanding "marginal" perspectives: Towards a so- cial theory of resilience. Qualitative Social Work. 2009;8:321-339.

24. Masten AS. Resilience in developing systems: Progress and promise as the fourth wave rises. Development \& Psychopathology. 2007;19:921-930.

25. Windle G, Bennett KM, Noyes J. A methodological review of resilience measurement scales. Health \& Quality of Life Outcomes. 2011;9:8-25.

26. Cicchetti D, Rappaport J, Sandler I, Wessberg RP. (Eds.). The promotion of wellness in children and adolescents. Washington, DC: CWLA Press. 2000.

27. Liebenberg L, Ungar M. Resilience in action. Toronto, Ontario: Toronto Press. 2008.

28. Ungar M, Liebenberg L. Assessing resilience across cultures using mixed methods: Construction of the child and youth resilience measure. Journal of Mixed Methods Research. 2011;5:126-149.

29. Liebenberg L, Ungar M, Van de Vijver F. Validation of the Child and Youth Resilience Measure-28 (CYRM-28) among Canadian youth. Research of Social Work Practice. 2012;22:219-226.

30. Turnbaugh KR, Guitar BE, Hoffman PR. Speech Clinicians' Attribution of Personality Traits as a Function of Stuttering Severity. Journal of Speech Language and Hearing Research. 1979;22:37.

31. Davis S, Howell P, Cooke F. Sociodynamic relationships between children who stutter and their non-stuttering classmates. Journal of Child Psychology \& Psychiatry \& Allied Disciplines. 2002; 43:939-947.

32. Cream A, Onslow M, Packman A, Llewellyn G. Protection from harm: The experience of adults after therapy with prolongedspeech. International Journal of Language \& Communication Disorders. 2003;38:379.

33. Blood GW, Blood IM, Maloney K, Meyer C, Qualls CD. Anxiety levels in adolescents who stutter. Journal of Communication Disorders. 2007;40:452-469.

34. Iverach L, Menzies RG, O’Brian S, Packman A, Onslow M. Anxiety and Stuttering: Continuing to explore a complex relationship. American Journal of Speech-Language Pathology. 2011;20:221232.

35. Blood GW, Blood IM. Bullying in adolescents who stutter: Communicative competence and self-esteem. Contemporary Issues in Communication Science and Disorders. 2004;31:69-79.

36. Evans D, Healey EC, Kawai N, Rowland S. Middle school students' perceptions of a peer who stutters. Journal of Fluency Disorders. 2008;33:203-219.

37. Langevin M, Kleitman S, Packman A, Onslow M. The Peer Attitudes Toward Children who Stutter (PATCS) scale: An evaluation of validity, reliability and the negativity of attitudes. International Journal of Language \& Communication Disorders. 2009;44:352368.

38. Blood GW, Blood IM, Tellis GM, Gabel, RM. Communication apprehension and self-perceived communication competence in adolescents who stutter. Journal of Fluency Disorder. 2001;26:161178.

39. Betz IR, Blood GW, Blood IM. University students' perceptions of pre-school and kindergarten children who stutter. Journal of 
Communication Disorders. 2008;41:259-273.

40. Garrett A. Bullying in American schools: Causes, preventions, interventions. Jefferson, NC: McFarland. 2003.

41. Rigby K. Effects of peer victimization in schools and perceived social support on adolescent well-being. Journal of Adolescence. 2000;23:57.

42. Solberg ME, Olweus D. Prevalence estimation of school bullying with the Olweus Bully/Victim Questionnaire. Aggressive Behavior. 2003;29:239-268.

43. Hixon S. Psychosocial Processes Associated with Bullying and Victimization. Humanistic Psychologist. 2009;37:257-270.

44. Cook S, Howell P. Bullying in children and teenagers who stutter and the relation to self-esteem, social acceptance, and anxiety. Perspectives on Fluency and Fluency Disorders. 2014;24:46.

45. Alm PA. Stuttering in relation to anxiety, temperament, and personality: Review and analysis with focus on causality. Journal of Fluency Disorders. 2014;40:5-21.

46. Maciejewski PK, Prigerson HG, Mazure CM. Self-efficacy as a mediator between stressful life events and depressive symptoms. British Journal of Psychiatry. 2000;174:373-378.

47. Kendler KS, Myers J, Prescott CA. Sex differences in the relationship between social support and risk for major depression: A longitudinal study of opposite-sex twin pairs. American Journal of Psychiatry. 2005;162:250-256.

48. Kessler RC, Price RH, Wortman CB. Social factors in psychopathology: Stress, social support, and coping processes. Annual Review of Psychology. 1985;36:531.

49. Drucker KC, Mazzucchellia TG, Beilby JM. An evaluation of an integrated fluency and resilience program for early developmental stuttering disorders. Journal of Communication Disorders. 2019; 78:69-83.

50. Plexico LW, Erath S, Shores H, Burrus E. Self-acceptance, resilience, coping and satisfaction of life in people who stutter. Journal of Fluency Disorders. 2019;59:52-63.

51. Chun RYS, Mendes CD, Yaruss JS, Quesal RW. The impact of stuttering on quality of life of children and adolescents. Pró-Fono Revista de Atualização Científica. 2010;22:567-570.

52. Yairi E, Ambrose NA. Early childhood stuttering. Austin, TX: ProEd. 2005.

53. Riley GD. Stuttering severity instrument for children and adults (SSI-4) (4th ed.). Austin, TX: Pro Ed. 2009.

54. Seccombe K. "Beating the Odds" versus "Changing the Odds": Poverty, resilience, and family policy. Journal of Marriage \& Family. 2002;64:384-394.

55. Ungar M. Pathways to resilience among children in child welfare, corrections, mental health and educational settings: Navigation and negotiation. Child \& Youth Care Forum. 2005;34:423-444.

56. Rutter M. Psychosocial resilience and protective mechanisms. American Journal of Orthopsychiatry. 1987;57:316-331.

57. Liebenberg L, Ungar M, LeBlanc JC. (2013). The CYRM-12: A brief measure of resilience. Canadian Journal of Public Health. 2013; 104:131-135.

58. Terwee CB, Bot SDM, de Boer MR, van der Windt DAWM, Knol
DL, Dekker J, et al. Quality criteria were proposed for measurement properties of health status questionnaires. Journal of Clinical Epidemiology. 2007;60:34-42.

59. Conture E. Stuttering: Its nature diagnosis and treatment. Boston: Allyn \& Bacon. 2001.

60. Smith A, Kelly E. Stuttering: A dynamic, multifactorial model. In R. Curlee and G. Siegel (eds). Nature and treatment of stuttering: New directions. Boston: Allyn \& Bacon. 1997;204-217.

61. Beilby JM, Byrnes ML, Yaruss JS. Acceptance and commitment therapy for adults who stutter: Psychosocial adjustment and speech fluency. Journal of Fluency Disorders. 2012;37:289-299.

62. Blumgart E, Tran Y, Scott Yaruss J, Craig A. Australian normative data for the Overall Assessment of the Speaker's Experience of Stuttering. Journal of Fluency Disorders. 2012;37:83-90.

63. Koedoot C, Versteegh M, Yaruss JS. Psychometric evaluation of the Dutch translation of the Overall Assessment of the Speaker's Experience of Stuttering for adults (OASES-A-D). Journal of Fluency Disorders. 2011;36:222-230.

64. Zebrowski P. (n.d.). The application of the transtheoretical model of behavior change among adolescents who stutter [scholarly project]. In The University of Iowa Stuttering Research Lab. 2014.

65. Avci G, Hanten G, Schmidt A, Li X, Orsten K, Faber J, Newsome MR. Cognitive contributors to resilience in youth from underserved populations: A brief report. Journal of Public Mental Health. 2013; 12:165-170.

66. Ferro MA, Boyle MH. Brief report: Testing measurement invariance and differences in self-concept between adolescents with and without physical illness or developmental disability. Journal of Adolescence. 2013;36:947-951

67. Crone EA. Executive functions in adolescence: Inferences from brain and behavior. Developmental Science. 2009;12:825-830.

68. Marsh HW, Craven R. Structure, stability, and development of young children's self-concepts: A multicohort-multioccasion study. Child Development. 1998;69:1030.

69. Robins RW, Fraley RC, Roberts BW, Trzesniewski KH. A longitudinal study of personality change in young adulthood. Journal of Personality. 2001;69:617-640.

70. Clark DA, Beck AT. Cognitive theory and therapy of anxiety and depression: Convergence with neurobiological findings. Trends in Cognitive Sciences. 2010;14:418-424.

71. Porto P, Oliveira L, Mari J, Volchan E, Figueira I, Ventura P. Does cognitive behavioral therapy change the brain: A systematic review of neuroimaging in anxiety disorders. Journal of Neuropsychiatry of Clinical Neuroscience. 2009;21:114-125.

72. Fry J, Millard S, Botterill W. Effectiveness of intensive, group therapy for teenagers who stutter. International Journal of Language \& Communication Disorders. 2014;49:113-126.

73. Jokic'-Begic' N. Cognitive- behavioral therapy and neuroscience: Towards closer integration. Psychological Topics. 2010;19:235254.

74. Masten CL, Eisenberger NI, Borofsky LA, Pfeifer JH, McNealy K, Mazziotta JC, et al. Neural correlates of social exclusion during adolescence: Understanding the distress of peer rejection. Social 
Cognitive \& Affective Neuroscience. 2009;4:143-157.

75. Terras MM, Thompson LC, Minnis H. Dyslexia and psycho-social functioning: an exploratory study of the role of self-esteem and understanding. Dyslexia. 2009;15:304-327.

76. Antia SD, Reed S, Shaw L. Risk and resilience for social competence: Deaf students in general education classrooms. Resilience in Deaf Children. 2011;139-167.

77. Lukow HR, Godwin EE, Marwitz JH, Mills A, Hsu NH, Kreutzer JS. Relationship between resilience, adjustm ent, and psychological functioning after traumatic brain injury. Journal of Head Trauma Rehabilitation. 2015;30:241-248. 


\section{Appendix A}

Participant numbers and ages, Section I OASES scores pre-intervention, Section II OASES scores pre-intervention, Section III OASES scores pre-intervention, Section IV OASES scores pre-intervention, and group average

\begin{tabular}{lcccc}
\hline Participant number \& age & $\begin{array}{c}\text { I. General } \\
\text { information }\end{array}$ & $\begin{array}{c}\text { II. Reactions to } \\
\text { stuttering }\end{array}$ & $\begin{array}{c}\text { III. Communication in daily } \\
\text { situations }\end{array}$ & $\begin{array}{c}\text { IV. Quality } \\
\text { of life }\end{array}$ \\
\hline P1- 10:6 & 2.53 & 2.65 & 2.33 & 1.50 \\
P2- 11:3 & 2.60 & 2.30 & 2.50 & 1.80 \\
P3- 11:8 & 2.60 & 2.40 & 2.00 & 2.10 \\
P4- 13:2 & 2.93 & 2.32 & 2.45 & 1.20 \\
P5- 17:2 & 1.90 & 1.72 & 2.25 & 1.20 \\
Group average & 2.51 & 2.28 & 2.31 & 1.56 \\
\hline
\end{tabular}

Participant numbers and ages, Section I OASES scores post-intervention, Section II OASES scores post-intervention, Section III OASES scores post-intervention, Section IV OASES scores post-intervention, and group average

\begin{tabular}{lcccc}
\hline Participant number \& age & $\begin{array}{c}\text { I. General } \\
\text { information }\end{array}$ & $\begin{array}{c}\text { II. Reactions to } \\
\text { stuttering }\end{array}$ & $\begin{array}{c}\text { III. Communication in daily } \\
\text { situations }\end{array}$ & $\begin{array}{c}\text { IV. Quality } \\
\text { of life }\end{array}$ \\
\hline P1- 10:6 & 2.10 & 2.60 & 2.50 & 1.30 \\
P2- 11:3 & 2.90 & 2.45 & 2.10 & 1.80 \\
P3- 11:8 & 2.53 & 2.40 & 2.27 & 1.10 \\
P4- 13:2 & 2.50 & 2.30 & 2.20 & 1.00 \\
P5- 17:2 & 1.86 & 1.76 & 2.10 & 1.35 \\
Group average & 2.38 & 2.31 & 2.23 & 1.53 \\
\hline
\end{tabular}




\section{Appendix B}

Lesson 1- Intro to Resilience: The researcher began by educating the adolescents on the concept of resiliency and explained the neurobiology of resilience. The adolescents then discussed how resiliency is developed and why it is important.

Lesson 2- The ABCs of Resilience: The researcher introduced the adolescents to the ABCs of resilience. This technique is rooted in positive psychology (Seligman, 2007). The foundation of resilience is built on the simple realization that our emotions and subsequent reactions are triggered not by events themselves, but by our interpretation of these events. Thus, labeling the ABCs of adversities associated with developmental stuttering was a meta-cognitive approach that provided the adolescents a greater understanding of the recurrent situations in which they were least resilient.

Lesson 3- Avoiding Thinking Traps: The researcher introduced the adolescents to the concept of thinking traps. The adolescents learned about 8 negative thinking traps and identified which thinking traps they most often fell into when they faced an adverse situation.

Lesson 4- Identifying Iceberg Beliefs: The researcher introduced the adolescents to the concept of iceberg beliefs. The goal of detecting iceberg beliefs was targeted to increase awareness of the beliefs that unwittingly caused them to overreact in particular situations, undermined their decision making, and caused them to over- experience a particular emotion. The researcher then discussed three general categories into which iceberg beliefs could fall: achievement, acceptance, and control. Using a variety of descriptors, the students had to match the descriptors to the proper category. The students then determined which category they most often fell into and discussed how it impacted their decisions and emotions.

Lesson 5- Challenging Beliefs: Here, the researcher introduced the adolescents to the concept of flexible thinking and taught a method for challenging initial beliefs by analyzing the cause of the beliefs and accuracy of the beliefs. The adolescents identified thinking traps influencing these beliefs and then developed alternative outcomes that differed from the initial belief.

Lesson 6- Optimism versus Pessimism: The researcher discussed optimism and pessimism. The adolescents then completed a questionnaire and evaluated whether they exhibit more optimistic thinking or pessimistic thinking. The adolescents then discussed how this could impact their emotional responses and reactions to stuttering.

Lesson 7- Self Esteem: Identifying your signature strengths and weaknesses: Here, the researcher introduced the adolescents to the concept of signature strengths. Like the ABCs in Lesson 2, signature strengths also are rooted in positive psychology (Seligman, 1992). The adolescents then completed a questionnaire and identified their top signature strengths, as well as areas for improvement. Following this exercise, the adolescents then presented to the group on their top strengths and identified ways they can use those strengths to make the world a better place. They also discussed ways in which they could improve on their areas of weakness.

Lesson 8- Social Support: Dealing with peers, teachers, and parents: The researcher introduced the adolescents to the concept of social support. The adolescents engaged in discussion on how social support could enhance resilience. Then, the adolescents identified people in their circle of support and discussed how these people could help them overcome various adversities associated with stuttering. The researcher also discussed with the adolescents how to positively cope and react to bullying.

Lesson 9- Resilience Profile: The researcher provided a template which synthesized the previous 8 lessons into one cohesive narrative. The adolescents completed the blanks and individualized their resiliency profile. These profiles were read aloud to the parents during final presentations at the last session.

Lesson 10- Resilience Quiz: The researcher provided a quiz that tested the adolescent's knowledge on the various concepts addressed in the curriculum. 